International Journal of English Language Studies (IJELS)

ISSN: 2707-7578

DOI: 10.32996/ijels

Website: https://al-kindipublisher.com/index.php/ijels

\title{
Strategies of Subtitling the Word Fuck in The Wolf of Wall Street Movie
}

Adi Sutrisno ${ }^{1 *}$ and Nizar Ibnus ${ }^{2}$

${ }^{12}$ Department of Languages and Literature, Universitas Gadjah Mada, Indonesia

Corresponding Author: Adi Sutrisno, E-mail: adisutrisno@ugm.ac.id

\section{ARTICLE INFORMATION}

Received: December 07, 2020

Accepted: February 21, 2021

Volume: 3

Issue: 2

DOI: 10.32996/ijels.2021.3.2.5

\section{KEYWORDS}

Translation strategy, audiovisual translation, omission, softening, mollification

\section{ABSTRACT}

To determine the appropriate strategy for the translation of the word fuck and its variants in audio visual translation is indeed problematic. On the one hand, the translator is required to maintain the beauty of the literary value as reflected in the dialogues, including the usage of offensive swear words; on the other hand, he is obliged to comply with the provisions stipulated in government regulation number 13 year 2014 concerning film censorship agency, especially paragraph 6 article 25 which forbids the usage of vulgar, offensive, racist words that have the potential to ignite public unrest. This research is intended to investigate the choice of translation strategy made by the translator. The method used in this research is descriptive qualitative using data in the form of the word fuck and its variants with The Wolf of Wall Street movie as the data source. This study is also intended to compare the results of a similar study conducted by Hawel (2019) which is about the strategy of audiovisual translation from English to Arabic. The results showed that there are similarities in the frequency of the strategies used, namely omission and softening strategies, which reached $75 \%$ and $25 \%$ respectively in Hawel's research (2019), and omission and mollification strategies which reached $72.9 \%$ and $27.1 \%$ consecutively in this study. The word mollification in this research is similar to the word softening in Hawel's (2019).

\section{Introduction}

The translation of the word fuck and the strategy used by the audiovisual translators to translate the word into Indonesian is problematic as it involves two conflicting views. The first view states that the audiovisual translation must not contain words that are obscene and violate moral norms; while the second one insists that the audiovisual translator is must translate whatever words as they are, with the sole purpose of maintaining the strength of the selected words by the author in the source language (Hjort, 2009).

Apart from these two conflicting views, there are still internal conflicts faced internally by the audiovisual translators. On the one hand, they wish to express their freedom to translate any word that is regarded as the strength of a film (Allan and Burridge, 2006, p 13); on the other hand, their hearts remind them of other things that must be considered, such as the cultural values of politeness in the communities where they live (Hjort, 2009). This clash of values put translators into a dilemmatic situation in which they have to decide what strategy to use.

Censoring the word fuck or other inappropriate words in the audiovisual translation which are practised in different parts of the world (Rabadan , 2000; Hjort 2009; ternuda, 2004; Roca , 2004) indicates the high attention in the translation of that kind. For example, during Franco's reign in Italy,it is only a literary work by foreign writer and/ or harmless authors which was widely published, such as Richmal Crompton's Just Wiliam series or Agatha Christie's detective stories. These series do not contain any taboo words. The concern about censorship of swear words was also shown by the audiovisual translators in Finland. These translators have a natural censorship strategy, namely strong self-control against the presence of words that are inappropriate to speak in the source language that are deemed inappropriate for their culture. They believe that words that are inappropriate to utter and have no significance to the plot, especially if the information conveyed can be inferred from facial expressions or tone

K C AL-KINDI CENTER $\mathbf{R}$ FOR RESEARCH AND $\mathbf{R}$ D DEVELOPMENT Your gateway to world-class research

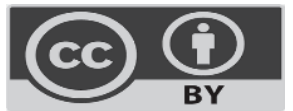

Published by Al-Kindi Center for Research and Development. Copyright (c) the author(s). This open access article is distributed under a Creative Commons Attribution (CC-BY) 4.0 license 
of voice, should be omitted from the text. They also believe that words whose meaning do not significantly affect the information presented in the dialogue can be censored and do not need to be translated (Zawanda, 2011).

Similar situation also occurred in Indonesia. The Film Censorship Agency in Indonesia carries out strict censorship of utterances that have the potential to raise moral and national integrity issues.

The Republic of Indonesia Government Regulation of 2014 Number 18 of Lembaga Sensor Film (LSF) or the Film Censorship Agency (in Chapter II Part Three containing about Functions and Powers of LSF Article 6 states that LSF has several duties including: a) censoring film and film advertisement before they are circulated and/or shown to the public; and b) conducting research and assessment of the title, theme, image, scene, sound, and text of the translation of a film and film advertisement that will be circulated and/or shown to public. In the same Chapter and Part, Article 25 section 1, 2, and 3 mentions the means and the purposes of censorship. Article 25 (1) Censorship of films and film advertisement is carried out based on the principle of dialogue with the owner of the censored film and film advertisement. (2) Apart from the matters referred to verse (1), censorship is also intended as a means of preserving the values and culture of the nation so that it can be maintained and developed in accordance with the personality of the Indonesian nation. (3) Censorship as a chain of guidance is directed at fostering the ability to self-control among filmmakers in their work as an embodiment of their responsibility to the nation's dignity. Those are the provisions that must be considered by filmmakers, including the translators. If there is a violation of the articles stipulated in Government Regulation No. 18 of 2013, the film will be withdrawn from circulation (Chapter III Part 5 article 38).

This LSF policy has an impact on the attitudes of Indonesian audiovisual translators in translating extreme words such as the word fuck and other offensive words from English into Indonesian. The translators do not translate the word as it is, but it is adapted to the context and follows the provisions that apply in Indonesia.

From the above description, it can be concluded that the word fuck is indeed not an ordinary word. In translation, this word requires caution as there are national cultural values that must be considered on the one hand, and there are demands for freedom of expression on the other hand. In terms of research, this study on the audiovisual translation strategy for the Word Fuck in The Wolf of Wall Street was inspired by a similar study in Iraq which examined the use of audiovisual translation strategies from English to Arabic. Arabic and Indonesian language do not have similarity in grammar, but the majority of people form those countries share the same Islamic values. In Islamic values, every Muslim must have akhlaq or morals that teach them to do good deeds and avoid bad deeds including saying bad words. Otherwise, they will sin. However, if the translators use taboo words for translation, they actually merely transfer the word from the source language to the target language. It does not necessarily mean they say taboo words for their own wishes. The translator's internal conflict in choosing a translation strategy is assumed to affect the translation results. In the Indonesian context, translators will be bound by the Government Institution Regulations on film censorship in terms of both the language in the film and the language in the film translation. This factor makes audiovisual translation in Indonesia, especially for films that use a lot of vulgar or taboo words, very challenging. Therefore, this research requires a clear problem formulation related to the word fuck in the source language and the strategies used by the audiovisual translator to transfer the word into the target language: (1) what causes someone to say the word fuck and what is the intention?; and (2) what strategy does the translator use to translate the word fuck and phrases containing the word fuck in it?

\section{Theoretical framework}

The word fuck and translation strategy in audiovisual translation are keywords that require theoretical explanations so that this research can provide a comprehensive picture as well as being the main foundation of this research. Therefore, this section discusses the words fuck, translation strategy, and audiovisual translation respectively.

\subsection{The word fuck}

The word fuck and phrases which contains the word fuck are words and phrases standings in the most offensive insults gradation, according to Ofcom research in 2016 in the UK (Mitchell, 2018). From a survey conducted on 200 people in England, Ofcom mapped swear words into four gradations, namely: mild, medium, strong, and strongest. Included in the level (a) mild are arse, bloody, damn, God, Jesus Christ, and goddamn; (b) medium includes: arsehole, bitch, bollocks, bullshit, pissed/pissed off, shit, son of a bitch, and tits; (c) strong includes bastard, bellend, cock, dick, dickhead, prick, pussy, snatch, and twat; and the most offensive or (d) the strongest is fuck, and motherfucker (Mitchell, 2018).

Even though the word fuck is included as the most offensive word (Mitchell I 2018), in pragmatic studies this word is not always offensive. According to Wajnryb (2005: 26), fuck words and other swear words can be classified based on the basic functions, namely: (1) cathartic, (2) abusive, and (3) social. Cathartic swear word can be defined as an emotional outburst of anger or an expression of intense hurt feelings; abusive swear word is directed at a specific target to either a person or an object; and social swear word can be defined as a way of expressing intimacy in the form of a joke. 
Previously, Trudgill and Andersson (1990: 61) categorized the word fuck and other swear words also in the same three basic functions but in slightly different terms, namely: (1) expletive, (2) abusive, and (3) humorous. Expletive swear word is used to express a burst of emotion and is not aimed at others. Abusive swear word is meant to hurt the person being targeted. Humorous swear word is similar to abusive one, but it is meant for joking.

The taxonomy of swear words based on pragmatic functions is also expressed by Ljung (1986, in Stenström et al. 2002: 77) and Pinker (2007). Ljung divides the word fuck and other swear words into two groups, namely: (1) aggressive swearing which expresses an explosive emotion, and (2) social swearing for the purpose of familiarizing; while Pinker describes the word swearing into five types: (1) descriptive swearing (2) idiomatic swearing, (3) abusive swearing, (4) emphatic swearing, and (5) cathartic swearing.

In pragmatic standpoint, it is safe to say that the word fuck not merely represent an offensive swear word. It can be very offensive when used to attack interlocutors or is often referred to as an abusive act (Trudgill and Anderson, 1990: Wajnryb, 2005; Pinker, 2007). However, it also has other meanings when used in different contexts, such as in social or humorous swearing which is often used when joking (Trudgill and Anderson, 1990; Wajnryb 2005); or in emphatic swearing (Pinker, 2007) which is used to emphasize certain words, such as That is fucking amazing painting (the painting was really amazing). Thus, the translation strategy of the word fuck and its variants in audiovisual translation will affect the quality of the translation in the target language. What is a translation strategy?

\subsection{Translation strategy}

In general, strategy can be said as certain steps that are prepared to get the desired results (Bandler, 2008). In relation to translation, the strategy can be said to be a mechanism that exists within the translator to deal with the concrete translation problems faced by translator in transferring the source text into the target text in order to get the expected results. (see Krings, 1986: 18). In line with Krings' view, Loescher (1991: 8) defines a translation strategy as a conscious and measured mechanism or step to overcome the problems faced in translating a text, or part of a text. Thus, the translation strategy is an effort made consciously by the translator to overcome the problem of translation from the source text into the target text by using considerations that are believed to get the expected results. According to Cohen (2014: 4), this conscious effort is what distinguishes the strategy from other translation processes that do not consider a particular strategy.

In translation studies, there are several views on translation strategies that are used as a theoretical basis for analyzing problems in translation, including Sequinot (1989), Baker (2018), Jaaskelainen (2005), Federici \& Federici (2011), and Hjort (2009). Among these views, Baker (2018) and Hjort's (2009) are most frequently used in translation studies. Both of them also share the essential similarities. The difference between the two is Baker outlines the translation strategies in detail, while Hjort describes them in general. Baker's (2018) translation strategies are as follows:

- Translation by a more general word

- Translation by a more neutral/less expressive word

- Translation by cultural substitution

- Translation using a loan word or loan word plus explanation

- $\quad$ Translation by paraphrase using a related word

- Translation by paraphrase using unrelated words

- Translation by omission

- Translation by illustration

These strategies are widely used in translation studies, including as a basis for writing an undergraduate thesis and a graduate thesis in Indonesia; especially a thesis that discusses translation strategies. However, this study does not use Baker's specifically to analyze the findings of the research. It is only used as an explanation when needed. The translation strategies used in the analysis of this research is the strategies by Hjort (2009). Hjort (2009) used these strategies to analyze the translation of swear words in audiovisual translation, namely omission and mollification. Omission is a translation strategy to eliminate certain parts of the sentence, either words or phrases, that are considered potentially cause culture shock when translated into the target language; while mollification is a translation strategy by using words or phrases that are not the same as the words used in the source text with the intention to mollify (mollification) the translation results so that they do not conflict with the culture or values that exist in society where the target language is used.

2.3 Audiovisual translation

Chiaro (2020) explains that audiovisual translation is the process of transferring a verbal component from one language to another that is contained in an audiovisual work or product. Thus, audiovisual translation is not the same as ordinary translation 
because in audiovisual translation there are additional conditions that must be considered. One of the conditions is the fact that one line in an audiovisual screen contains only 35 characters with a reading speed of 12 characters per second (Ivarsson and Carrol, 1998). This means that translators must be very careful in choosing the audiovisual translation strategy used so that they can transfer the source text into the target text appropriately. In this audiovisual translation process, a translator is usually given a script or dialogue in the source language.

According to Zubiria (2013: 93-98) in audiovisual products, the most commonly displayed feature is dialogue. The dialogue contains data complexity that could make audiovisual translators work extra hard, such as the appearance of interjection words, culturally different rhymes in jokes, elliptical sentence forms, and grammatical distortion. Translators must be able to capture and render all of them into the target language using relatively equivalent without reducing the meaning contained in the dialogue.

\section{Previous research}

A research on audiovisual translation strategies of swear words was conducted by Hawel (2019) focusing on translation of the word fuck and its variants in The Wolf of Wall Street movie. The main objective of this research is to investigate how translator get around the strategies used to translate these swear words from English into Arabic. The challenges faced by the translators of this film are manifold. First, The Wolf of Wall Street was recorded as the box office movie containing the most of swear words. The film was produced in 2013 by director Martin Scorsese, a well-known film director in the United States. Second, the subtitles of the film are translated into Arabic for the consumption of viewers in Arab countries. In these countries the population adheres to the Islamic religion which in their daily life highly upholds Islamic values. These two things put the translator in a problematic situation. On one hand this film contains a lot of swear words, on the other hand the translator must consider the values of Arab society in his translation. Table 1 shows an example of the strategy used in audiovisual translation from English into Arabic.

\begin{tabular}{|c|c|c|c|c|}
\hline & Source Text & Target Text & Back Translation & Strategy \\
\hline 1 & $\begin{array}{l}\text { You can } \\
\text { the fucking spotted } \\
\text { with money. }\end{array}$ & 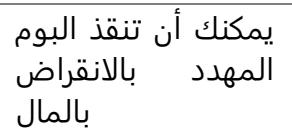 & $\begin{array}{l}\text { You can save } \\
\text { endangered owls with } \\
\text { money }\end{array}$ & Omission \\
\hline 2 & I fucking love that & يعجبني هذا & I like this. & Omission \\
\hline 3 & $\begin{array}{l}\text { Nobody knows if a stock's } \\
\text { going up, down } \\
\text { or fucking circles }\end{array}$ & 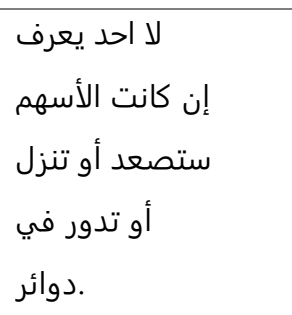 & $\begin{array}{l}\text { Nobody knows if a } \\
\text { stock's going up, down } \\
\text { or circles }\end{array}$ & Omission \\
\hline 4 & $\begin{array}{l}\text { We are taking home cold } \\
\text { heart cash via commission } \\
\text { motherfucker }\end{array}$ & خقبض المال نقدا من العمولة اليها & $\begin{array}{l}\text { Receive money in cash } \\
\text { through commission, } \\
\text { you stupid }\end{array}$ & Softening \\
\hline 5 & $\begin{array}{l}\text { Holy fuck you did just say } \\
\text { that. }\end{array}$ & اللعنة لقد قلت هذا .لتوك & $\begin{array}{l}\text { Damn it, you did just } \\
\text { say that. }\end{array}$ & Softening \\
\hline
\end{tabular}

Table 1 The translation strategies of audiovisual texts containing the word fuck from English into Arabic

Table 1 shows the choice of strategies used by the translator in translating the swear words represented by the word fuck and its variants. The translator removes the word fuck/fucking in sentences 1,2 , and 3 . In sentences 4 and 5 , the translator does not remove the word fuck/fucking but translates it using a word that has a lower degree than the word fuck/fucking in the target language. The results of Hawel's research show that the most widely used strategies are the deletion/omission strategy which is $75 \%$ and the softening strategy as much as $25 \%$. 


\section{Methods}

The descriptive qualitative method was used in this study to explain and analyze research data. The data of this research are the words and phrases fuck taken from the audiovisual translation of the film The Wolf of Wall Street as the data source. As the movie with the most swear words based on the Guinness World Records (Park, 2018), the number of the word fuck in this movie is abundant. The source language of the data is English; while the target language is Indonesian. The film was downloaded from https://nonton.movie/online/the-wolf-of-wall-street-262013-subtitle-indonesia-2aae/play and from DVD. English subtitle was downloaded from https://subscene.com/subtitles/the-wolf-of-wallstreet/english/1247746 and Indonesian subtitle was downloaded from https://subscene.com/subtitles/the-wolf-of-wallstreet/indonesian/881991.

The research procedure was carried out as follows: (1) watching carefully the film The Wolf of Wall Street to get a complete picture of the contents of the film; (2) watching the film The Wolf of Wall Street again while observing the use of words and phrases fuck; (3) reading the film script in English; (4) recording words or phrases fuck; (5) reading the Indonesian translated text while identifying the translation of words and phrases fuck; (6) identifying the translation strategies by comparing the source text and the target text and grouping them into tables; and (7) interpreting the data and concluding.

\section{Results}

The identification results of the research data indicate a high rate of the use of the words or phrase fuck. No less than 506 fuck words and their variants are found in the film The Wolf of Wall Street. The data analysis shows that not all of these words and phrases are offensive. The word fuck can be very offensive when used against other people, as in the expression Fuck you! but in a different context this word only acts as an intensifier or a word that gives emphasis on following word, like in the utterance Well, isn't that just fucking convenient for you? These two different samples of the use show that what makes someone say the word fuck is the situation created in a speech event. A student may say fuck all of sudden as he gets angry at himself after realizing that today is the due date of an assignment and he hasn't even started yet; someone could also say fuck/fucking when commenting on a beautiful goal created by his favorite football player, such as in the expression That goal is fucking fantastic. Thus, what underlies a person saying the word fuck or its variants is a stimulus that is present on his mind or something that appears unexpectedly before his eyes that makes him angry at himself (expletive/cathartic), angry at others (abusive), or just to express closeness with the interlocutor (social), to joke (humorous), and to give emphasis on what he is saying (intensifying/emphasizing).

The data analysis shows that $21 \%$ of the words and phrases fuck in the film The Wolf of Wall Street have abusive function; $75 \%$ of them express social function; while the rest function as catharsis as much as $4 \%$. The findings show the variety of the word fuck meanings contained in the film The Wolf of Wall Street.

This pragmatic analysis gives the translator choices in opting for translation strategy that is considered appropriate. How is the translation strategy of the word fuck used in the audiovisual translation of the film The Wolf of Wall Street from English to Indonesian? Are there any similarities in the choice of strategies used by the audiovisual translators from English to Arabic and English to Indonesian?

As described in the previous research on audiovisual translation strategy from English to Arabic, the most frequently used strategy is deletion/omission. This strategy is considered the most realistic and is in favor of the values of religiosity of the Arab society which uphold morals or maintain good attitudes and good speech (Hawel, 2019). In the process of translation, the translator decides to remove the word fuck and its variants as much as $75 \%$. The remaining $25 \%$ are translated using softening strategy or by reducing the degree of offensiveness of the word fuck and its variants. What about the audiovisual translation strategy carried out in the same film with translation from English to Indonesian?

The results show that there are similarities between the English to Arabic and English to Indonesian translations.

\begin{tabular}{lllll}
\hline & Source Text & Target Text & Back Translation & Strategy \\
\hline 1 & $\begin{array}{l}\text { Get your fucking hands } \\
\text { off me! }\end{array}$ & Lepaskan tanganmu! & Get your hands off me. & Omission \\
\hline 2 & Shut the fuck up. & Tutup mulutmu. & Shut up. & Omission \\
\hline 3 & $\begin{array}{l}\text { Well, isn't that } \\
\text { just fucking convenient } \\
\text { for you! }\end{array}$ & $\begin{array}{l}\text { Bukankah sungguh } \\
\text { nyaman bagimu? }\end{array}$ & $\begin{array}{l}\text { Well, isn't that just } \\
\text { convenient for you! }\end{array}$ & Omission \\
\hline 4 & Fuck. & Sial. & Damn. & Cultural substitution \\
\hline
\end{tabular}




5 Nobody gives a fuck. Tiada yang peduli. Nobody cares. Neutral

Table 2 Audiovisual translation strategies from English to Indonesian

Table 2 shows the strategies used by the translator in the film The Wolf of Wall Street from English to Indonesian. Deletion/omission strategy is more widely adopted than mollification strategy. Out of 506 the words and phrases fuck, 368 (72.9\%) of them are translated using the omission strategy and 137 using the mollification strategy.

\section{Discussion}

\begin{tabular}{|c|c|c|c|c|}
\hline & Source Text & Target Text & Back Translation & Strategy \\
\hline 1 & $\begin{array}{l}\text { Get your fucking hands } \\
\text { off me! }\end{array}$ & Lepaskan tanganmu! & Get your hands off me. & Omission \\
\hline 2 & Shut the fuck up. & Tutup mulutmu. & Shut up. & Omission \\
\hline 3 & $\begin{array}{l}\text { Well, isn't that } \\
\text { just fucking convenient } \\
\text { for you! }\end{array}$ & $\begin{array}{l}\text { Bukankah sungguh } \\
\text { nyaman bagimu? }\end{array}$ & $\begin{array}{l}\text { Well, isn't that just } \\
\text { convenient for you! }\end{array}$ & Omission \\
\hline 4 & Fuck. & Sial. & Damn. & Cultural substitution \\
\hline 5 & Nobody gives a fuck. & Tiada yang peduli. & Nobody cares. & Neutral \\
\hline
\end{tabular}

Table 3 Audiovisual translation strategies of the text containing the word fuck from English into Indonesian

The examples shown in table 3 present the translator's caution in selecting translation strategy to use. The omission strategy is used to translate the word fuck and its variants in utterances 1,2 and 3. Utterances 1 and 2 have similarities in terms of the moods. There is a sense of anger in utterance 1 which is indicated by the presence of the word fucking and the exclamation mark. In this translation, the translator uses omission strategy by eliminating the word fucking in Get your fucking hands off me into Lepaskan tanganmu! This translation is understandable and close to its original meaning, but it still leaves something less revealed. The choice of the word lepaskan highly depends on the syllable stress that is applied to the utterance (strong stress) as a means of compensating for the sense of anger that is expressed in the word fucking and the exclamation mark. The translator may be able to use another word that reflects someone's displeasure or anger when it is uttered, such as Get rid of your hand! It means that the translator actually has two choices, namely using the omission or mollification strategy with a cultural substitution strategy and the translator chooses the former. Utterance 2 also contains a tone of anger which is reflected in the use of imperative sentence coupled with the word fucking. Omission strategy is used in this utterance to eliminate the word fucking which then becomes Tutup mulutmu! When this utterance is delivered in the right tone, between English utterance that uses the word fuck and Indonesian utterance that eliminates the word fuck can still be felt equivalent. A different nuance occurs in the utterance 3 that is Well, isn't that fucking convenient for you. The presence of the word fucking in this utterance is intended to emphasize the word convenient. As there is no strong impression of anger, offensiveness does not appear clearly in this utterance. Interestingly, in the source language the word fucking is also used in that context. The translator omits the word fucking in the translation without reducing the meaning of the utterance.

Even though omission does not interfere the lexical meaning of a sentence, it could eliminate emotive value of the sentence (Molina \& Hurtado Albir, 2002). The emotion of the swear word is not conveyed when omitted. The abusive function of the word fuck loses the most when this strategy is implemented. When the word fuck that has abusive function is omitted in the target language, it will become an ordinary sentence with no emotion. In greater frequency, it could alter the mood of the film. Whereas, The Wall of Wall Street film relies a lot on swear words because these words are used to portray the glamorous yet violent life on Wall Street.

In utterances 4 and 5, the translator uses mollification strategy. This strategy is used when a translator does not want to take risks when he has to translate vulgar words that have the potential to violate the provisions stipulated in Government Regulation Number 13 of 2014 concerning censorship by the Film Censorship Institution, or moral values such as maintaining attitudes and speech for not utter bad words. In utterance 4, fuck is difficult for the translator to remove because there are no other words to accompany it. If the word fuck is omitted, nothing can be said in the translation, thereby reducing the intensity in the dynamics of the dialogue. The translator uses a mollification strategy that is by having equivalents which offensive level is below the word fuck. In this case, the word sial is chosen as a translation of the word fuck. This is a cultural substitution. Utterance 5 that is Nobody gives a fuck was also transferred to Indonesian using the mollification strategy. This strategy is used to soften the word fuck in the sentence. Mollification strategy is used to neutralize the utterance by using the phrase with the same basic idea in the target language, namely Tiada yang peduli which when translated back into Nobody cares. This strategy is an attempt by the 
translator to avoid the risk of violating Government Regulation No. 13 of 2014 Chapter II Article 6, and Chapter III Article 25 section 2 and 3 .

Mollification can be done in various ways, one of which is cultural substitution. This is a way that can provide the translation results that are closest to the meaning of the original swear word, because cultural substitution puts forward the similarity in the impact of the word being translated (Baker, 2018: 30). Therefore, the function of the translated swear word can still be conveyed even though it is not completely. Even though the frequency of omission outnumbers mollification, the use of cultural substitution could help to preserve the mood and emotion of the film.

The use of neutral word also appears in the translation of the word fuck in The Wolf of Wall Street film. Even though the lexical meaning is preserved well by this strategy, the function of the translated swear word disappears when this strategy is used. Whereas, the beauty of film is not merely reflected on the screen but also on the dialogue the audience heard. The Wolf of Wall Street film stands out and is remembered for one thing because it dares to use a lot of swear words; something that many other films do not.

\section{Conclusion}

Translation strategies of the word fuck in audiovisual translation of The Wolf of Wall Street movie included omission and mollification strategy to replace vulgar and offensive words with relatively safe words. The main consideration in choosing these strategies is because LSF prohibits translators from using vulgar, offensive, and racist words as well as words that have the potential to destabilize security. The findings in this study are in agreement with those conducted in Iraq, namely the high frequency of use of omission strategy. In the previous research on the strategies used in audiovisual translation from English to Arabic, it was found that there are $75 \%$ omission strategies and $25 \%$ softening or mollification strategies; meanwhile, in the research strategy used in the audiovisual translation from English to Indonesian using the same data source, there are $72.9 \%$ omission strategies and $25.1 \%$ mollification strategies. The similar results from these two studies confirm that the same social background of the target language society can actually result in the same translation form and orientation. This is even more so if these social values are maintained by legislation. For future research, another kind of research on the word fuck will be challenging. For instance, it will be interesting to investigate the prosodic features of the word fuck whether it is showing anger or just demonstrating the degree of closeness among the interlocutors. The data can be taken from movies which display quite a many swearwords, especially the word fuck. For this purpose, natural language processing can be proposed. This future researcher may collect the verbal data of the word fuck as much as he can, and apply machine learning algorithms on the verbal data to figure out whether the verbal data is related to "anger" or not. By this, evidence that the word fuck does not always represent anger can enrich people understanding about the word fuck. If that is to happen, subtitling the word fuck will become much easier.

\section{References}

[1] Allan, K., \& Burridge, K. (2006). Forbidden words: Taboo and the censoring of language. Cambridge University Press.

[2] Baker, M. (2018). In other words: A coursebook on translation. Routledge.

[3] Bandler, R. (2008). Richard Bandler's Guide to Trance-formation: How to Harness the Power of Hypnosis to Ignite Effortless and Lasting Change. Health Communications, Inc..

[4] Cernuda, M. Á. V. (2004). De la Guerra Civil al pasado inmediato. In Historia de la Traducción en España (pp. 527-578). Editorial Ambos Mundos.

[5] Chiaro, D. (2012). Audiovisual translation. The encyclopedia of applied linguistics, 1-6.

[6] Cohen, A. D. (2014). Strategies in learning and using a second language. Routledge.

[7] Federici, F. M., \& Federici, F. M. (2011). Translating dialects and languages of minorities: Challenges and Solutions. Peter Lang.

[8] Hawel, Z. S. (2019). Strategies of Subtitling Swear words in The Wolf of Wall Street Movie. Lark Journal for Philosophy, Linguistics and Social Sciences, 3(34), 423-432.

[9] Hjort, M. (2009). Swearwords in Subtitles-A Balancing Act. In inTRAlinea: Special Issue: The Translation of Dialects in Multimedia (2009).

[10] Ivarsson, J., \& Carroll, M. (1998). Subtitling. TransEdit.

[11] Jaaskelainen, R. (2005). Translation studies: what are they. Retrieved November, 11, 2006.

[12] Krings, H. P. (1986). Translation problems and translation strategies of advanced German learners of French (L2). Interlingual and intercultural communication, 272, 263.

[13] Loescher, W. (1991). Translation Performance, Translation Process and Translation Strategies. Guten Narr.

[14] Mitchell, B. (2018, February 9). This is Ofcom's ranking of swear words in order of offensiveness. Digital Spy. https://www.digitalspy.com/tv/a809925/ofcom-swear-words-ranking-in-order-of-offensiveness/

[15] Molina, L., \& Hurtado Albir, A. (2002). Translation techniques revisited: A dynamic and functionalist approach. Meta: Journal des Traducteurs/Meta: Translators' Journal, 47(4), 498-512.

[16] Park, M. (2018). Analyzing translation strategies of swear words used in subtitle Translation focusing on The Wolf of Wall Street. The Journal of Translation Studies, 19(3), 81-112.

[17] Pinker, S. (2007). The stuff of thought: Language as a window into human nature. Penguin. 
[18] Rabadán, R. (2000). Traducción y censura inglés-español: 1939-1985: estudio preliminar. Universidad de Léon.

[19] Roca, M. G. (2004). De las vanguardias a la Guerra Civil. In Historia de la Traducción en España (pp. 479-526). Editorial Ambos Mundos.

[20] Seguinot, C. L. C. (1989). The Translation Process. HG Publications.

[21] Stenström, A. B., Andersen, G., \& Hasund, I. K. (2002). Trends in Teenage Talk: Corpus Compilation, Analysis and Findings. John Benjamins Publishing.

[22] Trudgill, P., \& Lars-Gunnar, A. (1990). Bad Language. Basil Blackwell Limited.

[23] Wajnryb, R. (2005). CU Next Tuesday: A Good Look at Bad Language. White Lion Publishing.

[24] Zawanda, E. (2011). Strategies for translation of swearwords in audiovisual material and how they influence the viewers' perception: On the example of the Polish version of Dexter.

[25] Zubiria, J. B. (2012). Mapping the dubbing scene: Audiovisual translation in Basque television. Peter Lang. 